\title{
Intraoperative aortic root pressure study for quantitative assessment of aortic regurgitation during valve-sparing root replacement: A preliminary report
}

\author{
Yuki Ikeno, MD, Hiroshi Tanaka, MD, PhD, and Yutaka Okita, MD, PhD, Kobe, Japan
}

From the Department of Cardiovascular Surgery, Kobe University, Kobe, Japan.

Disclosures: Authors have nothing to disclose with regard to commercial support.

Received for publication Oct 16, 2017; revisions received March 28, 2018; accepted for publication March 30, 2018; available ahead of print May 12, 2018.

Address for reprints: Yutaka Okita, MD, PhD, Division of Cardiovascular Surgery, Department of Surgery, Kobe

University Graduate School of Medicine, 7-5-2 Kusunoki-cho Chuo-ku, Kobe 650-0017, Japan (E-mail: yutakaokita@gmail.com).

J Thorac Cardiovasc Surg 2018;156:1399-401

$0022-5223 / \$ 36.00$

Copyright (c) 2018 by The American Association for Thoracic Surgery

https://doi.org/10.1016/j.jtcvs.2018.03.168

(f) Supplemental material is available online.

$\downarrow$ Video clip is available online.

Residual aortic regurgitation (AR) after valve-sparing root replacement (VSRR) is an important complication. ${ }^{1}$ Assessment of the repair quality, however, largely depends on intraoperative visual inspection and transesophageal echocardiography (TEE). We previously reported a reproducible method of detecting AR with a videoscope ${ }^{2}$; however, this technique does not provide a quantitative estimate. This study aimed to analyze the diagnostic accuracy of an aortic root pressure test in evaluating AR during VSRR.

\section{PATIENTS AND METHODS}

Forty-five patients underwent VSRR with a reimplantation technique between July 2015 and March 2017. The intraoperative pressure test was used in 32 cases, and the clinical data were analyzed retrospectively. The study protocol was approved by the institutional review board, with informed consent waived because of the design of the study.

The algorithm of assessment is shown in Figure E1. Even in cases of suboptimal results of the pressure test, the surgeon determined whether to proceed to TEE assessment on the basis of visual inspection and aortic clamping time. AR was graded according to the American Society of Echocardiography recommendations as none, trace, mild, moderate, or severe. ${ }^{3}$

Technical details of the assessment are shown in Video 1. The aortic root was replaced with a Valsalva graft (Terumo Medical, Somerset, NJ). Before coronary implantation, the distal edge of the Valsalva graft was clamped, with great care taken to avoid inducing deformation, and the neosinus was pressurized with the crystalloid cardioplegic solution by means of a roller pump at the rate of $200 \mathrm{~mL} / \mathrm{min}$, as measured by the circuit pressure

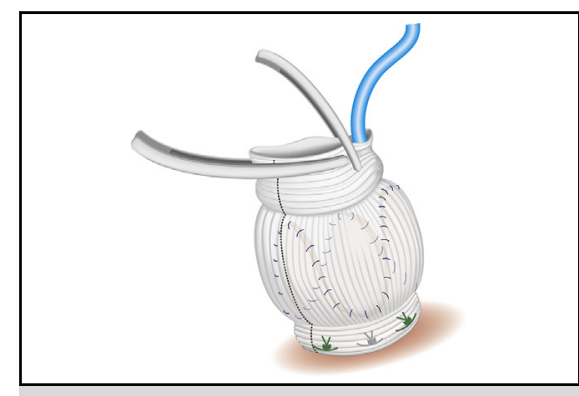

Depiction of pressurizing neosinus and circuit pressure monitoring.

Central Message

An aortic root pressure test that is based on the mean pressure buildup had a high diagnostic accuracy for evaluating aortic regurgitation.

See Editorial Commentaries pages 1402 and 1404.

(CP) monitoring at the cardiopulmonary bypass machine (Figure E2). CP was plotted every 0.5 seconds to capture the trend graph (Figure $1, A$ ). Implantation of the coronary arteries and distal anastomoses were completed after confirming the aortic cusp competency. After weaning from cardiopulmonary bypass, residual AR was determined by TEE.

\section{Definition of the Mean Pressure Buildup}

We set the $\mathrm{CP}$ assessment in the range of $50 \mathrm{~mm} \mathrm{Hg}$ (the nadir of the pressure curve, $P_{\min }$ ) to $200 \mathrm{~mm} \mathrm{Hg}$ (the maximum of the pressure curve, $\left.P_{\max }\right)$. Thereafter, the scope of assessment of time was set between the time corresponding to $\mathrm{P}_{\min }\left(T_{\min }\right)$ and $\mathrm{P}_{\max }\left(T_{\max }\right)$. Mean pressure buildup ( $m P B$, in $\mathrm{mm} \mathrm{Hg} / \mathrm{s}$ ) was defined as the pressure change during pressurization divided by the pressurization time (Figure $1, B$ ):

$$
m P B(\mathrm{~mm} \mathrm{Hg} / \mathrm{s})=\left(P_{\max }-P_{\min }\right) \div\left(T_{\max }-T_{\min }\right)
$$

\section{Statistical Analyses}

All continuous variables were expressed as the median with the interquartile range (IQR; 25th-75th percentile). The mPB values across the AR grade were assessed with the Kruskal-Wallis test. The Wilcoxon rank sum test was used for post hoc analysis. A $P$ value of less than .05 was considered statistically significant. All data analyses were performed with JMP 11.0 (SAS Institute Inc, Cary, NC).

\section{RESULTS}

Patient characteristics are shown in Table 1. Eight patients underwent the pressure test at least 2 times (median, 


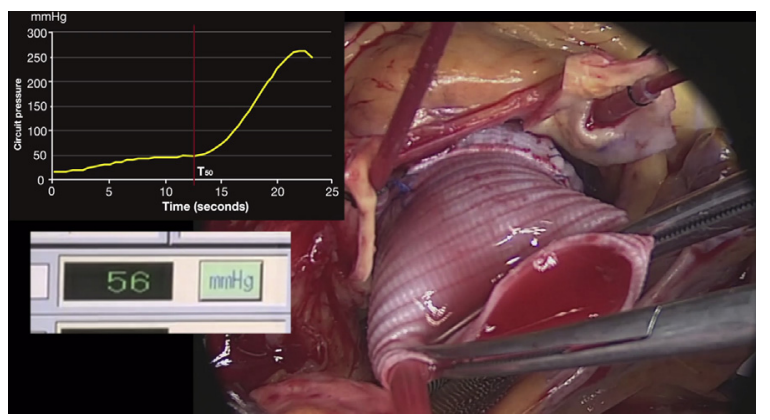

VIDEO 1. After the second row suture and cusp repair (central plication of right coronary cusp) under cardiac arrest, we inspected the coaptation of the aortic cusp. Then, the aortic root pressure was assessed by administering crystalloid cardioplegia solution with the help of a roller pump (at the rate of $200 \mathrm{~mL} / \mathrm{min}$ ). The distal edge of the Valsalva graft was clamped with 2 forceps. After the clamping, the neosinus was pressurized, as measured by the circuit pressure monitoring at the cardiopulmonary bypass machine. In this patient, the circuit pressure showed a rapid rise beyond $200 \mathrm{mmHg}$. The mean pressure buildup $(m P B)$ was calculated by the following equation:

$$
\begin{aligned}
m P B(\mathrm{~mm} \mathrm{Hg} / \mathrm{s}) & =\left(P_{\max }-P_{\min }\right) \div\left(T_{\max }-T_{\min }\right) \\
& =(200 \mathrm{~mm} \mathrm{Hg}-50 \mathrm{~mm} \mathrm{Hg}) \div(19.5 \mathrm{~s}-13.0 \mathrm{~s}) \\
& =23.1 \mathrm{~mm} \mathrm{Hg} / \mathrm{s}
\end{aligned}
$$

where $P_{\max }$ is maximum circuit pressure (cutoff of $200 \mathrm{~mm} \mathrm{Hg}$ ), $P_{\min }$ is minimum circuit pressure (cutoff of $50 \mathrm{~mm} \mathrm{Hg}$ ), $T_{\min }$ is time at minimum circuit pressure, and $T_{\max }$ is time at maximum circuit pressure. Postprocedural transesophageal echocardiography (TEE) showed no aortic regurgitation. Video available at: https://www.jtcvs.org/article/S0022-5223(18)31021-3/fulltext.
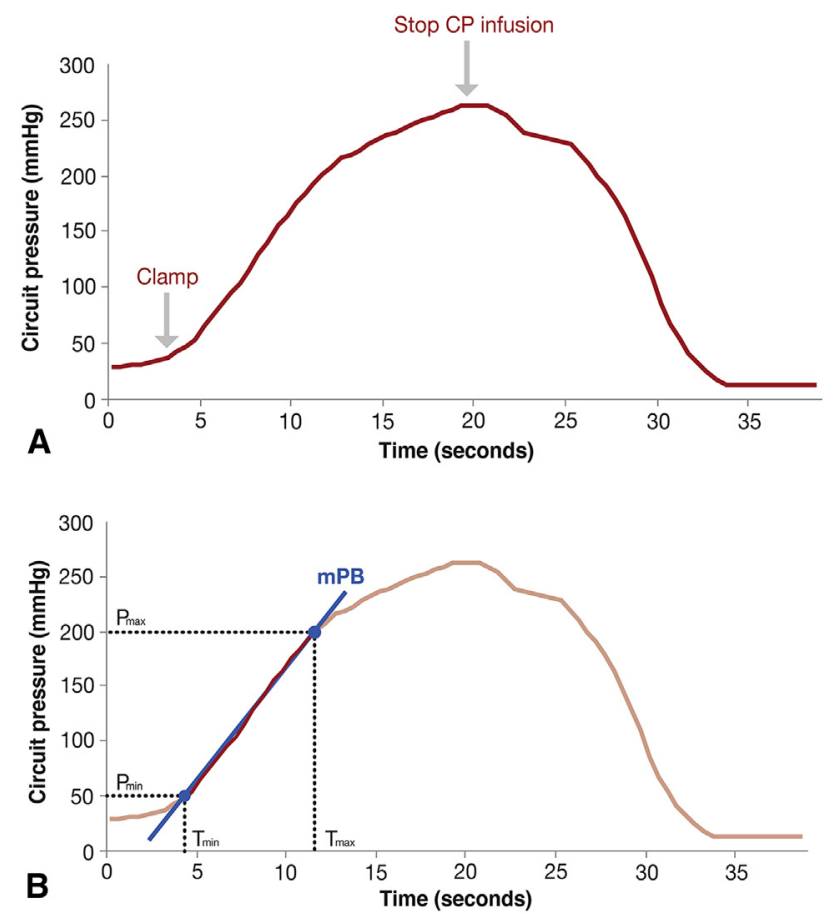

FIGURE 1. A, Trend graph of circuit pressure. B, Definition of mean pressure buildup $(m P B)$. $C P$, Cardioplegia; $P_{\max }$, maximum pressure $(200 \mathrm{~mm} \mathrm{Hg}) ; P_{\text {min }}$, minimum pressure $(50 \mathrm{~mm} \mathrm{Hg}) ; T_{\text {min }}$, time at mini-

\begin{tabular}{|c|c|}
\hline Variable & Value \\
\hline \multicolumn{2}{|l|}{ Preoperative } \\
\hline Age (y) & $54.0(45.3-65.5)$ \\
\hline Male sex & $27(84.4 \%)$ \\
\hline $\operatorname{BSA}\left(\mathrm{m}^{2}\right)$ & $1.69(1.63-1.82)$ \\
\hline \multicolumn{2}{|l|}{ Symptoms } \\
\hline NYHA I & $14(43.8 \%)$ \\
\hline NYHA II & $16(50.0 \%)$ \\
\hline NYHA III & $2(6.2 \%)$ \\
\hline Previous cardiac surgery & $5(15.6 \%)$ \\
\hline Urgent operation & $1(3.1 \%)$ \\
\hline \multicolumn{2}{|l|}{ Aortic valve morphology } \\
\hline Quadricuspid & $2(6.2 \%)$ \\
\hline Tricuspid & $22(68.8 \%)$ \\
\hline Bicuspid & $6(18.8 \%)$ \\
\hline Autograft & $2(6.2 \%)$ \\
\hline \multicolumn{2}{|l|}{ AR grade } \\
\hline None & $1(3.1 \%)$ \\
\hline Trace & $3(12.5 \%)$ \\
\hline Mild & $1(3.1 \%)$ \\
\hline Moderate & $2(6.2 \%)$ \\
\hline Severe & $25(78.1 \%)$ \\
\hline Cusp prolapse & $20(62.5 \%)$ \\
\hline $\operatorname{LVEF}(\%)$ & $55.8 \%(45.8 \%-63.4 \%)$ \\
\hline LVDd (mm) & $61.6(56.7-67.7)$ \\
\hline LVDs (mm) & $43.7(37.7-52.3)$ \\
\hline $\mathrm{AVJ}(\mathrm{mm})$ & $25.8(23.5-27.6)$ \\
\hline Valsalva sinus (mm) & $44.1(39.1-50.8)$ \\
\hline $\mathrm{STJ}(\mathrm{mm})$ & $34.9(31.3-46.7)$ \\
\hline \multicolumn{2}{|l|}{ Intraoperative and postoperative } \\
\hline \multicolumn{2}{|l|}{ Implanted graft size } \\
\hline $24 \mathrm{~mm}$ & $3(9.4 \%)$ \\
\hline $26 \mathrm{~mm}$ & $7(21.9 \%)$ \\
\hline $28 \mathrm{~mm}$ & $19(59.4 \%)$ \\
\hline $30 \mathrm{~mm}$ & $3(9.4 \%)$ \\
\hline Central plication & $21(65.6 \%)$ \\
\hline Free margin reinforcement & $11(31.3 \%)$ \\
\hline Patch repair & $3(9.4 \%)$ \\
\hline Cusp decalcification & $3(9.4 \%)$ \\
\hline Commissural plasty & $4(12.5 \%)$ \\
\hline Cardiopulmonary bypass time (min) & $220.5(188.8-260.5)$ \\
\hline Aortic clamping time (min) & $180.0(143.5-206.0)$ \\
\hline \multicolumn{2}{|l|}{ Postprocedural AR grade } \\
\hline None & $12(37.5 \%)$ \\
\hline Trace & $14(43.8 \%)$ \\
\hline Mild & $5(15.6 \%)$ \\
\hline Moderate & $0(0 \%)$ \\
\hline Severe & $1(3.1 \%)$ \\
\hline
\end{tabular}
mum pressure; $T_{\max }$, time at maximum pressure.
TABLE 1. Patient characteristics and operative variables $(n=32)$

Data are median with interquartile range or number of patients with percentage. $B S A$, Body surface area; NYHA, New York Heart Association functional class; $A R$, aortic regurgitation; $L V E F$, left ventricular ejection fraction; $L V D d$, left ventricular diameter, diastolic; $L V D s$, left ventricular diameter, systolic; $A V J$, aortoventricular junction; STJ, sinotubular junction.

4.0 times; IQR, 2.5-6.3 times). The final value for $\mathrm{mPB}$ was $16.3 \mathrm{~mm} \mathrm{Hg} / \mathrm{s}$ (IQR, 12.-24.6 mm Hg/s). The $\mathrm{mPB}$ values were significantly lower in patients with mild or greater 


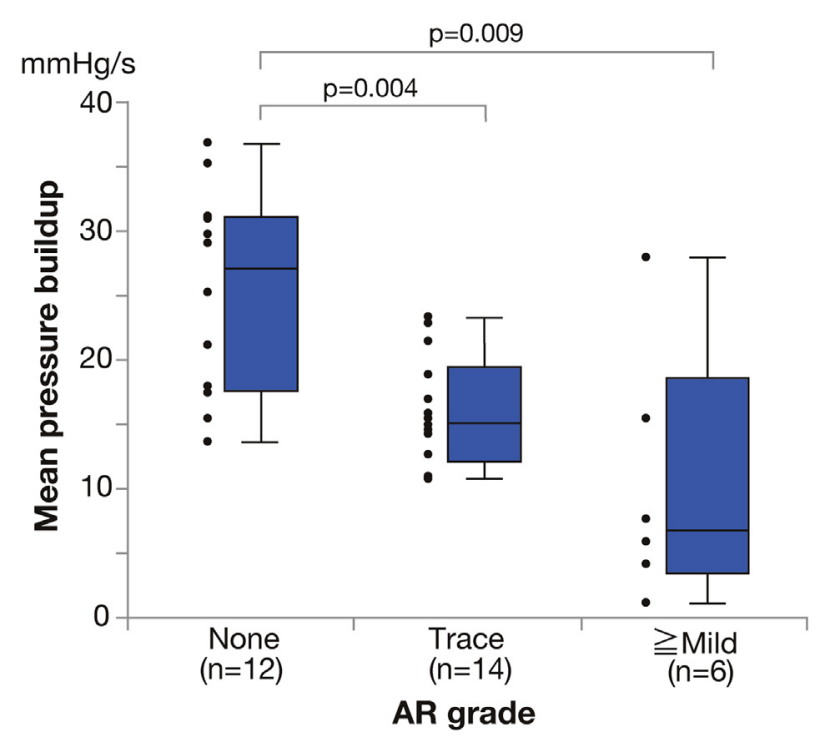

FIGURE 2. The mean pressure buildup for each grade of aortic regurgitation $(A R)$. Regarding postprocedural aortic regurgitation grade, the mean pressure buildup values were significantly lower in patients with mild or greater aortic regurgitation (median, $6.6 \mathrm{~mm} \mathrm{Hg} / \mathrm{s}$; interquartile range, $3.3-18.4 \mathrm{~mm} \mathrm{Hg} / \mathrm{s} ; P=.009)$ and patients with trace aortic regurgitation (median, $15.1 \mathrm{~mm} \mathrm{Hg} / \mathrm{s}$ (interquartile range, 12.1-19.4 mm Hg/s; $P=.004)$ relative to patients without aortic regurgitation (median, $27.0 \mathrm{~mm} \mathrm{Hg} / \mathrm{s}$ (interquartile range, 17.4-31.0 $\mathrm{mm} \mathrm{Hg} / \mathrm{s}$ ).

$\mathrm{AR}$ and trace AR compared with patients with no AR (Figure 2), and the results were similar in patients with tricuspid aortic valve $(\mathrm{n}=22$; Figure E3).

There were no in-hospital deaths. One patient required intraoperative conversion to aortic valve replacement because of thickened cusps causing severe AR (3.1\%). In 8 patients, modifications of cusp repair by removing $(\mathrm{n}=1)$ or adding suture $(\mathrm{n}=7)$ were performed. The $\mathrm{mPB}$ improved significantly after the modification (Figure E4). No patients underwent secondary aortic clamping.

\section{DISCUSSION}

The concept of the buildup test was based on our understanding of vacuum physics. Theoretically, in a closed circuit, leak volume is estimated by the pressure differential before and after leakage. We set the pressure changes in the neosinus as an indicator for AR. We set the minimum value of $\mathrm{CP}\left(\mathrm{P}_{\min }, 50 \mathrm{~mm} \mathrm{Hg}\right)$ on the basis of our previous experience with the difference between $\mathrm{CP}$ and the actual root pressure. Moreover, the maximum value of $\mathrm{CP}\left(\mathrm{P}_{\max }\right)$ was set at $200 \mathrm{~mm} \mathrm{Hg}$ to avoid pressure injury. Although $\mathrm{P}_{\max }$ may contribute to AR by itself, it is influenced by the pressurization time, graft size, and baseline pressure. We adopted $\mathrm{mPB}$ as our indicator.

A major disadvantage of postprocedural TEE is that modifications of repair can only be performed after declamping. The quantitative assessment without additional aortic clamps may significantly improve outcomes relative to visual inspection alone, because all 3 patients who proceeded to TEE with $\mathrm{mPB}$ lower than $10 \mathrm{~mm} \mathrm{Hg}$ were found to have mild AR. Judging from the results, we believe that $\mathrm{mPB}$ less than $10 \mathrm{~mm} \mathrm{Hg}$ was a reasonable cut-off value for detecting at least mild AR.

\section{CONCLUSIONS}

An aortic root pressure test that is based on $\mathrm{mPB}$ during VSRR had a high diagnostic accuracy for evaluating postprocedural residual AR.

\section{References}

1. Kari FA, Doll KN, Hemmer W, Liebrich M, Sievers HH, Richardt D, et al. Residual and progressive aortic regurgitation after valve-sparing root replacement: a propensity-matched multi-institutional analysis in 764 patients. Ann Thorac Surg. 2016;101:1500-6.

2. Miyahara S, Oka T, Takahashi H, Inoue T, Matsumori M, Tanaka H, et al. Feasibility of intraoperative water testing in aortic valve repair: Direct visualization from left ventricle with a videoscope. J Thorac Cardiovasc Surg. 2017;154:24-9.

3. Zoghbi WA, Enriquez-Sarano M, Foster E, Grayburn PA, Kraft CD, Levine RA, et al. Recommendations for evaluation of the severity of native valvular regurgitation with two-dimensional and doppler echocardiography. J Am Soc Echocardiogr. 2003;16:777-802. 


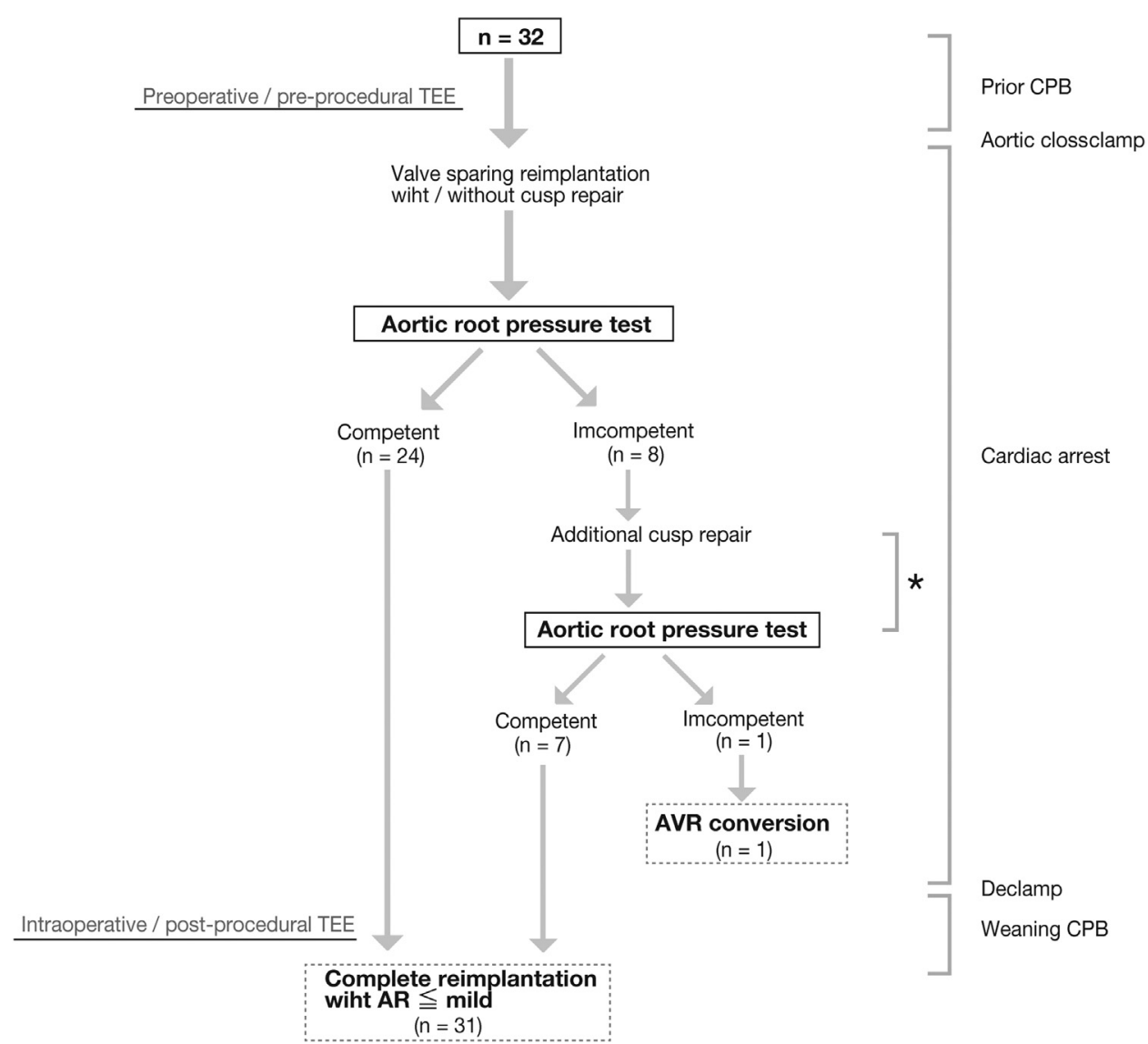

FIGURE E1. Algorithm of intraoperative management with aortic root pressure test. Asterisk indicates that additional cusp repair and aortic root pressure test were performed 1 or more times according to the result of the assessment. TEE, Transesophageal echocardiography; $C P B$, cardiopulmonary bypass; $A V R$, aortic valve replacement; $A R$, aortic regurgitation.

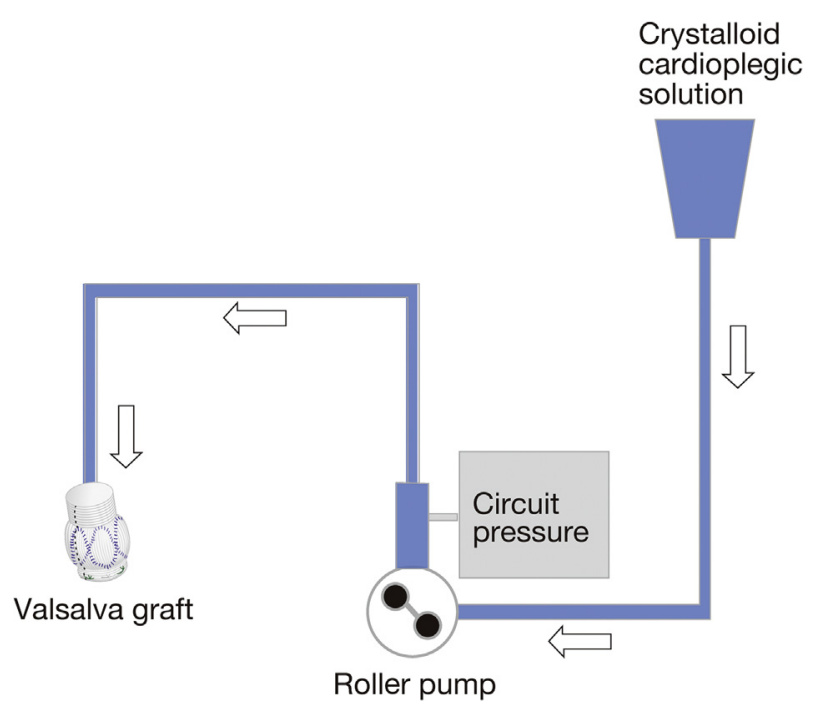

FIGURE E2. Schema of infusion of cardioplegic solution and circuit pressure monitoring. 
Tricuspid aortic valve

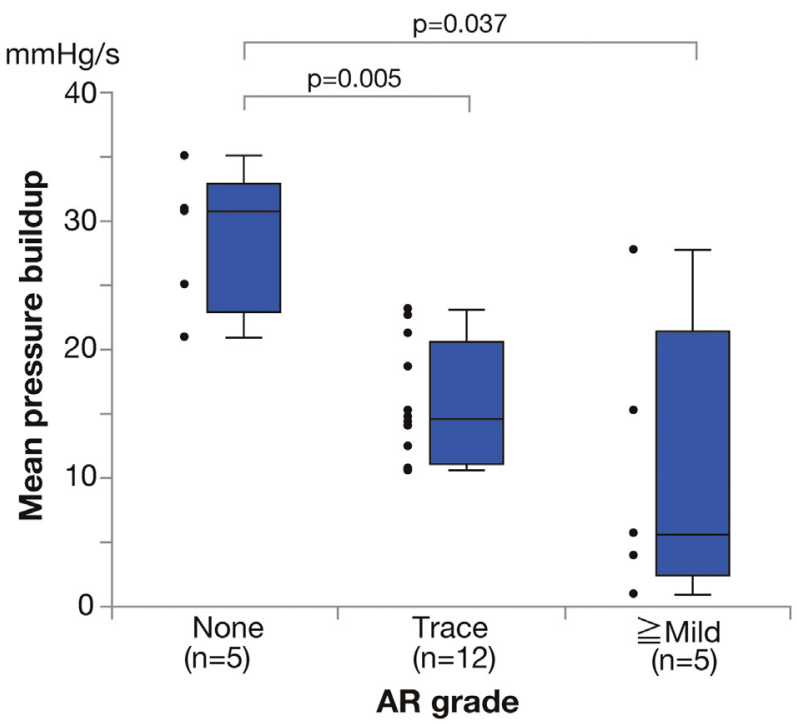

FIGURE E3. Postprocedural aortic regurgitation $(A R)$ in patients with tricuspid aortic valve $(\mathrm{n}=22)$. The mean pressure buildup was significantly lower in patients with mild or greater aortic regurgitation and trace aortic regurgitation compared with that in patients without aortic regurgitation (mild or greater aortic regurgitation, $\mathrm{n}=5$; median $\mathrm{mm} \mathrm{Hg} / \mathrm{s}, 5.7$; interquartile range, $2.5-21.6 \mathrm{~mm} \mathrm{Hg} / \mathrm{s} ; P=.005$; trace aortic regurgitation, $\mathrm{n}=12$; median, $14.6 \mathrm{~mm} \mathrm{Hg} / \mathrm{s}$; interquartile range, $11.2-20.7 \mathrm{~mm} \mathrm{Hg} / \mathrm{s}$; $P=.037$; without aortic regurgitation [reference], $\mathrm{n}=5$; median, $30.8 \mathrm{~mm} \mathrm{Hg} / \mathrm{s}$; interquartile range, $23.1-33.1 \mathrm{~mm} \mathrm{Hg} / \mathrm{s}$ ).

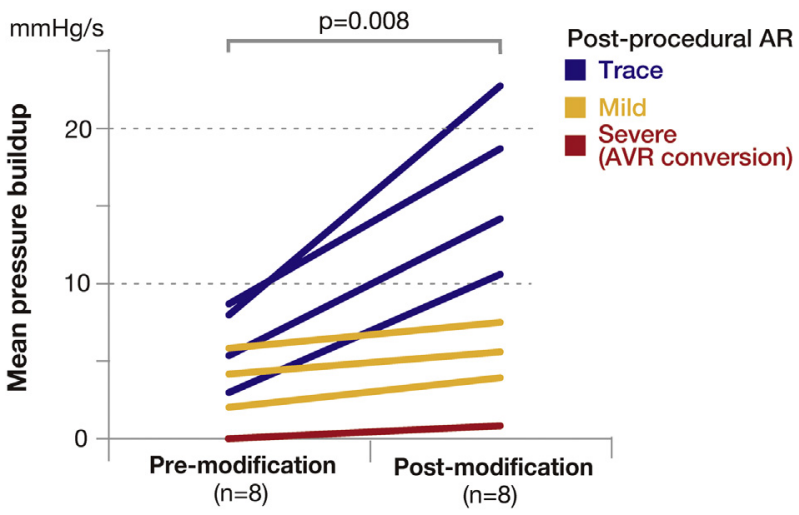

FIGURE E4. Mean pressure buildup for patients who underwent modification of cusp repair. The mean pressure buildup improved significantly after modification of cusp repair (premodification, median, $4.8 \mathrm{~mm} \mathrm{Hg} / \mathrm{s}$; interquartile range, $2.3-7.4 \mathrm{~mm} \mathrm{Hg} / \mathrm{s}$; postmodification, median, $9.1 \mathrm{~mm}$ $\mathrm{Hg} / \mathrm{s}$; interquartile range, 4.4-17.6 mm Hg/s, $P=.008$ ). AR, Aortic regurgitation; AVR conversion, conversion to aortic valve replacement. 